\title{
Relationship between HLA-DR Expression by Normal Myeloid Progenitor Cells and Inhibition of Colony Growth by Prostaglandin E Implications for Prostaglandin E Resistance in Chronic Myeloid Leukemia
}

\author{
Stephen A. Cannistra, Friedhelm Herrmann, Roger Davis, Kim Nichols, and James D. Griffin \\ Divisions of Tumor Immunology, Medicine and Biostatistics, Dana-Farber Cancer Institute, and the Department of Medicine, Harvard \\ Medical School, Boston, Massachusetts 02115
}

\begin{abstract}
The expression of HLA-DR antigens by normal myeloid progenitor cells (CFU-GM) has been linked to inhibition of colony growth by prostaglandin $\mathrm{E}$ (PGE), while resistance to the inhibitory effects of PGE in chronic myeloid leukemia (CML) has been attributed to a lower fraction of HLA-DR+ CFU-GM in this disease. However, we have previously shown that virtually all CFU-GM in normal bone marrow (NBM) as well as CML peripheral blood express HLA-DR antigens, which raises the possibility that these surface molecules may not be the sole determinants of a progenitor cell's sensitivity to PGE. In order to evaluate the relationship between HLA-DR expression and prostaglandin inhibition, we partially purified NBM progenitor cells using fluorescence-activated cell sorting to prepare cell fractions with high and low HLA-DR antigen density. Normal progenitor cells with high DR density tended to form monocyte colonies in agar culture, whereas the low DR density fraction was enriched for granulocyte colony-forming cells. Inhibition by PGE was greatest in the high DR+ fraction and was largely restricted to monocyte progenitor cells. Inhibition of CFU-GM by PGE was less in CML than in NBM, but this decreased inhibition correlated with a significantly lower number of monocyte-CFU in CML. These data suggest that high HLA-DR antigen density may select for normal progenitor cells that are committed to monocyte differentiation and are, therefore, more likely to be inhibited by PGE. The relative deficit of monocyte progenitor cells in CML may partially explain the phenomenon of PGE resistance in this disease.
\end{abstract}

\section{Introduction}

HLA-DR antigens are expressed on a variety of hematopoietic cells including B cells, activated $T$ cells, monocytes, and progenitor cells of the erythroid and myeloid lineages (1-6). These Ia-like antigens regulate cellular interactions of the immune response, but their role in the regulation of hematopoiesis is less clear (7-10). Recent reports have suggested that the inhibitory effects of acidic isoferritins or prostaglandin $E(P G E)^{1}$ on the

Address reprint requests to Dr. Griffin, Division of Tumor Immunology, Dana-Farber Cancer Institute.

Received for publication 17 April 1985 and in revised form 11 September 1985.

1. Abbreviations used in this paper: ANAE, alpha napthyl acetate esterase; CAE, chloroacetate esterase; CFU-GM, granulocyte/monocyte colony-

J. Clin. Invest.

(c) The American Society for Clinical Investigation, Inc. 0021-9738/86/01/0013/08 \$1.00

Volume 77, January 1986, 13-20 normal granulocyte/monocyte colony-forming cell (CFU-GM) appear to be restricted to those cells that express HLA-DR (11, 12). This is of particular interest because it has been reported that the fraction of DR + CFU-GM in chronic myeloid leukemia (CML) is lower than in normal bone marrow (NBM), and this has been linked to the resistance of CML progenitor cells to PGE $(12,13)$.

Different laboratories have varied widely in their determinations of the fraction of normal and CML CFU-GM that express HLA-DR, however, and the association of DR expression with sensitivity to PGE has not been universally accepted (14). It is possible that the extent to which CFU-GM are detected as DR+ may depend on the anti-DR antibody used and its capacity to fix complement, and thus CFU-GM with low DR antigen density would be negative in some studies and weakly positive in others. Unfortunately, complement lysis of CFU-GM is not an ideal technique to investigate DR antigen density, and little is known about biological or functional differences that exist between CFU-GM with low density or high density DR expression.

Previous studies in our laboratory and others with flow cytometry have shown that virtually all CFU-GM of both NBM and CML are DR+, and that the range of Ia antigen density is extremely broad $(15,16)$. In this report we describe the use of cell-sorting techniques to prepare populations of CFU-GM with different levels of DR antigen expression. These populations have been characterized functionally and used to examine the relationship of DR antigen density to PGE sensitivity. The results indicate that subsets of day 7 CFU-GM express different levels of HLA-DR depending upon their commitment to monocyte or granulocyte differentiation. High density DR + CFU-GM were enriched for monocyte progenitor cells, and these cells were more sensitive to PGE inhibition compared with granulocyte progenitor cells.

A parallel investigation of progenitor cell subsets and PGE sensitivity in NBM and CML was also done. Sensitivity to PGE inhibition was related to the proportion of monocyte progenitor cells present in either NBM or CML. The observation that overall inhibition by PGE tended to be less in CML may be partly a result of a relative deficiency of monocyte precursor cells in this disease.

\section{Methods}

Source of CFU-GMs. Peripheral blood samples $(5-10 \mathrm{ml})$ were obtained from stable-phase CML patients undergoing initial diagnostic testing.

forming cell; CML, chronic myeloid leukemia; FACS, fluorescence-activated cell sorting; FCS, fetal calf serum; G/M, granulocyte/monocyte; GCT, giant cell tumor conditioned medium; IMDMEM, Iscove's modified Dulbecco's minimal essential media; MEM, minimal essential media; NBM, normal bone marrow; $\mathrm{PGE}_{1}$, prostaglandin $\mathrm{E}_{1}$. 
After collection into sterile-heparinized syringes, the mononuclear cell fraction was separated by Ficoll-Hypaque diatrizoate gradient sedimentation, washed twice in minimal essential media (MEM; Gibco, Grand Island, $\mathrm{NY}$ ) containing $2.5 \%$ pooled human $\mathrm{AB}$ serum (MEM-AB wash), and cryopreserved in the vapor phase of liquid nitrogen in $10 \%$ dimethylsulfoxide and $20 \%$ heat-inactivated fetal calf serum (FCS) until use. Samples were thawed in the presence of $100 \mu \mathrm{g} / \mathrm{ml}$ deoxyribonuclease I (Worthington Biochemical Corp., Freehold, NJ) to minimize cell agglutination. Two CML samples were studied before cryopreservation with equivalent results.

NBM was aspirated from healthy volunteers into heparinized syringes after written consent was approved by the Institutional Review Board. The mononuclear cell fraction was separated by Ficoll-Hypaque diatrizoate gradient sedimentation as above.

Monoclonal antibodies. Monoclonal antibodies used in the purification of CML colony-forming cells have been previously characterized and include anti-MY8 (pan-myeloid) (17), anti-Mol (pan-myeloid) (18), anti-Mo2 (monocyte) (18), anti-B1 (B cell) (19), anti-T3 and anti-T11 (T cell) $(20,21), \mathrm{HNK} 1$ (natural killer cell) (22), and $31 \mathrm{C6}$ (basophil and natural killer cells) (Hercend, T., and J. Griffin, unpublished observation). Monoclonal antibodies used in the purification of NBM were similar, but also included an anti-glycophorin A monoclonal antibody (clone 39, Sabbath, K., and J. Griffin, unpublished observation).

Partial purification of myeloid progenitor cells. The method of myeloblast purification from the peripheral blood of CML patients has been previously reported and has also been applied to the partial purification of normal bone marrow CFU-GM (23). Briefly, 1-2 $\times 10^{8}$ mononuclear cells from either NBM or CML peripheral blood were incubated with the previously noted monoclonal antibodies for $30 \mathrm{~min}$ at $4^{\circ} \mathrm{C}$. After two wash steps, affinity-purified rabbit anti-mouse immunoglobulin coupled to sheep erythrocytes by chromic chloride was added $(0.7 \mathrm{ml}$ of $10 \% \mathrm{vol} / \mathrm{vol}$ erythrocytes in MEM-AB wash per $10^{8}$ cells). The erythrocyte-mononuclear cell mixture was pelleted $(800 \mathrm{~g}, 10 \mathrm{~min})$ and incubated at $4^{\circ} \mathrm{C}$ for $20 \mathrm{~min}$ for rosette formation. The rosetted cells were then separated from the nonrosetted cells (containing the progenitor cells) by density gradient sedimentation. Interface cells (unrosetted) were washed twice in MEM-AB. A cytocentrifuge preparation was examined to determine purity.

For CML peripheral blood, this technique typically resulted in a preparation of $85-95 \%$ blast forms with a colony-forming efficiency (CFU-GM) of $30-40 \%$. For NBM, partial purification usually resulted in a preparation of $\sim 30-50 \%$ blasts, $50 \%$ promyelocytes, $0-10 \%$ myelocytes, and 0-10\% early erythroid precursors, with a CFU-GM colonyforming efficiency of $\sim 10-20 \%$. For some experiments, monocytes were prepared from fresh peripheral blood by adherence as previously described (15).

Immunofluorescence analysis of HLA-DR. In order to determine the relationship of HLA-DR expression to CFU-GM commitment, partially purified progenitor cells from NBM were stained for DR antigen expression by an indirect immunofluorescence assay and subsequently sorted on the basis of HLA-DR antigen density. Briefly, $\sim 1 \times 10^{7}$ partially purified cells were washed twice in MEM-AB wash, and the pellet was then suspended in $1.0 \mathrm{ml}$ of diluted ascites. Monoclonal antibody 9-49, which identifies a monomorphic DR determinant (24), was used as a 1:250 dilution of ascites for these experiments (kindly provided by Dr. Robert Todd, University of Michigan, Ann Arbor, MI). After incubation for $30 \mathrm{~min}$ at $4^{\circ} \mathrm{C}$, the cells were washed twice and stained with fluorescein-conjugated goat anti-mouse Ig (Tago Inc., Burlingame, CA) for $30 \mathrm{~min}$ at $4^{\circ} \mathrm{C}$. After two additional wash steps, the cells were analyzed by flow microfluorimetry (FACS-I, Becton-Dickinson \& Co., Oxnard, $\mathrm{CA})$ and separated into a cell fraction with high DR antigen density $(40 \%$ of DR + cells with the brightest fluorescence) and a population with low DR density (40\% of DR + cells with the least bright fluorescence). Background fluorescence was measured using an isotype-identical control monoclonal antibody.

CFU-GM assay. Partially purified progenitor cells were plated at 1$2.5 \times 10^{3}$ cells/culture in Iscove's modified Dulbecco's MEM (IMDMEM), $20 \%$ FCS, $0.3 \%$ agar over an underlayer of $0.5 \%$ agar with
20\% GCT (Gibco) (15). Indomethacin (Sigma Chemical Co., St. Louis, $\mathrm{MO}$ ) at a final concentration of $10^{-6} \mathrm{M}$, was used in all CFU-GM assays to prevent the endogenous secretion of prostaglandin by small numbers of contaminating accessory cells. Indomethacin by itself did not affect number or type of CFU-GM. Prostaglandin inhibition was evaluated by using $\mathrm{PGE}_{1}$ (Sigma Chemical Co.) in the range of $10^{-6}-10^{-10} \mathrm{M}$ in agar. After 7 and $14 \mathrm{~d}$ of culture $\left(37^{\circ} \mathrm{C}, 5 \% \mathrm{CO}_{2}\right)$, the overlayers were removed and dried on glass microscope slides. They were subsequently fixed and stained for both naphthol AS-D chloroacetate esterase (CAE, granulocyte lineage) and alpha napthyl acetate esterase (ANAE, monocyte lineage) as previously described (25). Colonies ( $>40$ cells) and clusters (8-40 cells) were identified as granulocytic if all cells were CAE + , pure monocytic if all cells were ANAE + , and mixed if cells positive for both stains were present within a single colony or cluster. Using these criteria, $<5 \%$ of colonies and clusters from either CML or NBM could not be classified.

Liquid suspension culture. In order to exclude the possibility that the growth, differentiation, and staining characteristics of NBM and CML CFU-GM were altered by in vitro agar culture, partially purified NBM and $C M L$ peripheral blood were also grown in liquid suspension culture over a 7-14-d period. For each treatment group, $1 \times 10^{6}$ partially purified progenitor cells were suspended in $5 \mathrm{ml}$ of IMDMEM, 20\% FCS, $10 \%$ GCT (Gibco), $10^{-6} \mathrm{M}$ indomethacin, with or without $10^{-6} \mathrm{M} \mathrm{PGE}_{1}$ in a $60 \times 15$-mm petri dish (Falcon Laboratories, Oxnard, CA) on day 0 . On days 7 and 14 of culture $\left(37^{\circ} \mathrm{C}, 5 \% \mathrm{CO}_{2}\right)$, the cell population was counted, and cytocentrifuge smears were stained for combined esterase activity and with Wright-Giemsa stain.

Statistical analysis. Significance levels for comparison between treatment groups were determined using two-sided $t$ tests. Paired tests were used when appropriate. Significance levels for correlations were derived from the $t$ test conversion on the correlation coefficient $r$. The association between monocyte colony number and overall PGE inhibition was estimated by standard multiple regression techniques (26).

\section{Results}

Relationship of HLA-DR expression to CFU-GM commitment. In order to investigate the relationship between PGE inhibition and HLA-DR antigen expression, partially purified progenitor cells from NBM were separated into two fractions on the basis of HLA-DR antigen density by fluorescence-activated cell sorting (FACS) and assayed for CFU-GM in agar, with or without $10^{-6}$ $M P E_{1}$. In pilot experiments, it was shown that $>95 \%$ of CFU$\mathrm{GM}$ are recovered in the $\mathrm{DR}+$ fraction. Because of the small numbers of CFU-GM present in the DR - fraction, further analysis of that fraction was not undertaken. Colonies and clusters were counted on day 7 using combined esterase staining to detect monocyte colonies (ANAE+, CAE-) granulocyte colonies (ANAE-, CAE+), and mixed G/M (granulocyte/monocyte) colonies (ANAE+, CAE+). A typical FACS-I histogram of HLADR (9-49) expression in this cell population is shown in Fig. 1, and data from five experiments with different bone marrow donors are presented in Table I. In each case, both the absolute number and the relative percentage of pure monocyte colonies was greater in the high HLA-DR antigen group of CFU-GM. The mean percentage of monocyte colonies was significantly greater for the high density HLA-DR group ( $36 \pm 13$ vs. $3 \pm 3 \%$, $P<0.005$ ), as was the mean percentage of mixed $\mathrm{G} / \mathrm{M}$ plus monocyte colonies $(47 \pm 19$ vs. $11 \pm 10 \%, P<0.005)$.

Relationship of HLA-DR expression to PGE inhibition. In four of the five sorting experiments, the inhibitory effects of $10^{-6}$ $M$ PGE $_{1}$ on day 7 CFU-GM were assessed (Table II). In each case, the overall inhibition by $\mathrm{PGE}_{1}$ was greater in the high $\mathrm{DR}$ antigen density group, with the mean $\mathrm{PGE}_{1}$ inhibition being $37 \pm 8 \%$ for the high density and $4 \pm 13 \%$ for the low density $D R+$ 


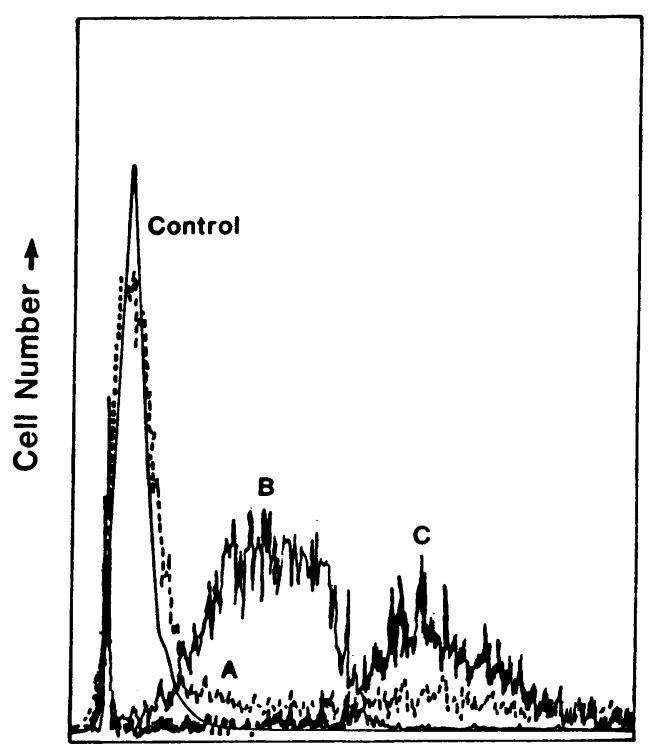

Fluorescence Intensity $\rightarrow$

Figure 1. Separation of partially purified NBM progenitor cells into high and low density DR + fractions by FACS. A, presort fluorescence histogram of HLA-DR as defined by 9-49 monoclonal antibody (34\% of cells are positive); B, postsort reanalysis of low density DR+ fraction $(99 \% \mathrm{DR}+)$; C, postsort reanalysis of high density DR+ fraction $(99 \% \mathrm{DR}+)$.

progenitor cells $(p=0.025)$. The inhibitory effects of $P G E_{1}$ on individual CFU-GM subsets, however, appeared to be similar for both DR density groups, with the greatest degree of inhibition being observed for monocyte colonies, a moderate degree of inhibition for mixed $\mathrm{G} / \mathrm{M}$ colonies, and the least amount of inhibition (and sometimes slight enhancement) for granulocyte colonies.
Despite the similar response of CFU-GM subsets in either $\mathrm{DR}+$ fraction to $10^{-6} \mathrm{M} \mathrm{PGE}_{1}$, we considered the possibility that the dose response of colony inhibition at lower $\mathrm{PGE}_{1}$ concentrations may differ between the low and high DR+ groups. In order to evaluate this possibility, sorted cells were plated in the presence of $P G E_{1}$ in a dose range of $10^{-6}-10^{-10} \mathrm{M}$, and the results of one such experiment are shown in Table III. As in previous experiments, high density HLA-DR+ CFU-GM were inhibited to a substantially greater degree than were low density HLA-DR + CFU-GM. This inhibition was restricted to monocyte and mixed CFU-GM. However, when CFU-GM subsets were analyzed individually, the degree of colony inhibition was similar for the low and high DR+ groups over a broad range of $\mathrm{PGE}_{1}$ concentrations. It should be noted that accurate quantitation of monocyte progenitor cell inhibition by PGE in the low density $\mathrm{DR}+$ fraction was limited by the extremely low number of monocyte colonies in this group (Table III).

Comparison of CFU-GM subsets in NBM and CML. The experiments described above suggested that inhibition of normal CFU-GM by PGE was partly determined by the proportion of CFU-GM committed to monocyte differentiation, and that the association between PGE sensitivity and DR expression could be due to the fact that monocyte-CFU expressed higher levels of DR antigen than granulocyte-CFU. In order to test this observation further, we evaluated the composition of CFU-GM subsets and their sensitivity to PGE in CML, a disease which is characterized by resistance to $P G E$ inhibition despite the presence of HLA-DR on the majority of CFU-GM (15).

Partially purified progenitor cells from NBM and CML peripheral blood were evaluated for colony and cluster formation on days 7 and 14, with the cumulative results of 18 experiments shown in Table IV. The percentage of ANAE positive colonies from NBM exceeded that of CML by a factor of 3.1 on day 7 ( $28 \pm 7$ vs. $9 \pm 6 \%, P=0.0006)$ and by a factor of 2.3 on day 14 ( $38 \pm 8$ vs. $16 \pm 12 \%, P=0.2$ ). Monocytes freshly prepared from

Table I. Relationship of HLA-DR Expression to CFU-GM Commitment in NBM*

\begin{tabular}{|c|c|c|c|c|c|c|c|c|}
\hline \multirow{3}{*}{$\begin{array}{l}\text { Experiment } \\
\text { number }\end{array}$} & \multicolumn{8}{|c|}{ HLA-DR antigen density } \\
\hline & \multicolumn{4}{|l|}{ Low } & \multicolumn{4}{|l|}{ High } \\
\hline & Gran & Mixed G/M & Mono & Total & Gran & Mixed G/M & Mono & Total \\
\hline 1 & $\begin{array}{l}182 \pm 5 \ddagger \\
(76) \S\end{array}$ & $\begin{array}{l}46 \pm 3 \\
(19)\end{array}$ & $\begin{array}{l}13 \pm 2 \\
(5)\end{array}$ & $241 \pm 7$ & $\begin{array}{l}42 \pm 3 \\
(31)\end{array}$ & $\begin{array}{l}18 \pm 4 \\
(13)\end{array}$ & $\begin{array}{l}77 \pm 3 \\
(56)\end{array}$ & $137 \pm 5$ \\
\hline 2 & $\begin{array}{l}133 \pm 10 \\
(91)\end{array}$ & $\begin{array}{l}6 \pm 2 \\
(4)\end{array}$ & $\begin{array}{l}7 \pm 2 \\
(5)\end{array}$ & $146 \pm 11$ & $\begin{array}{l}82 \pm 2 \\
(73)\end{array}$ & $\begin{array}{l}5 \pm 2 \\
(4)\end{array}$ & $\begin{array}{l}26 \pm 3 \\
(23)\end{array}$ & $113 \pm 5$ \\
\hline 3 & $\begin{array}{l}342 \pm 11 \\
(97)\end{array}$ & $\begin{array}{c}12 \pm 2 \\
(3)\end{array}$ & $\begin{array}{l}0 \pm 0 \\
(0)\end{array}$ & $354 \pm 12$ & $\begin{array}{l}318 \pm 15 \\
(63)\end{array}$ & $\begin{array}{l}68 \pm 4 \\
(13)\end{array}$ & $\begin{array}{l}120 \pm 10 \\
(24)\end{array}$ & $506 \pm 16$ \\
\hline 4 & $\begin{array}{l}122 \pm 11 \\
(81)\end{array}$ & $\begin{array}{l}19 \pm 1 \\
(13)\end{array}$ & $\begin{array}{l}9 \pm 1 \\
(6)\end{array}$ & $150 \pm 12$ & $\begin{array}{l}27 \pm 3 \\
(45)\end{array}$ & $\begin{array}{l}10 \pm 1 \\
(17)\end{array}$ & $\begin{array}{l}23 \pm 1 \\
(38)\end{array}$ & $60 \pm 4$ \\
\hline 5 & $\begin{array}{l}420 \pm 17 \\
(98)\end{array}$ & $\begin{array}{l}2 \pm 1 \\
(0.5)\end{array}$ & $\begin{array}{c}6 \pm 1 \\
(1.5)\end{array}$ & $428 \pm 17$ & $\begin{array}{l}159 \pm 14 \\
(52)\end{array}$ & $\begin{array}{c}29 \pm 5 \\
(9)\end{array}$ & $\begin{array}{l}119 \pm 4 \\
(39)\end{array}$ & $307 \pm 23$ \\
\hline Total (\%) & $89 \pm 10$ & $8 \pm 8$ & $3 \pm 3$ & & $53 \pm 16$ & $11 \pm 5$ & $36 \pm 13$ & \\
\hline
\end{tabular}

* Partially purified myeloid progenitor cells from NBM were divided into equal fractions of low and high density HLA-DR (9-49) positive groups by FACS (also see Fig. 1). Cells were subsequently plated in agar containing $10^{-6} \mathrm{M}$ indomethacin and $10 \%$ GCT as a source of colony-stimulating activity. Gran, granulocyte; mono, monocyte. ‡ Colony and cluster number and morphology per $10^{3}$ cells was determined on day 7 by combined esterase staining. Results are expressed as mean $\pm \mathrm{SE}$ of duplicate or triplicate cultures. $\S$ Numbers in parentheses indicates percentage. 


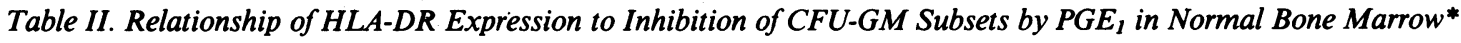

\begin{tabular}{|c|c|c|c|c|c|c|c|c|}
\hline \multirow{3}{*}{$\begin{array}{l}\text { Experiment } \\
\text { number }\end{array}$} & \multicolumn{8}{|c|}{ Percent inhibition of CFU-GM by PGE $_{1}(\%) \neq$} \\
\hline & \multicolumn{4}{|c|}{ Low density HLA-DR } & \multicolumn{4}{|c|}{ High density HLA-DR } \\
\hline & Gran & Mixed & Mono & Total & Gran & Mixed & Mono & Total \\
\hline 1 & 4 & 35 & 85 & 14 & -48 & 39 & 90 & 41 \\
\hline 2 & 10 & 17 & 57 & 12 & 13 & 20 & 92 & 32 \\
\hline 3 & -18 & 42 & NE§ & -15 & 2 & 34 & 96 & 29 \\
\hline 4 & 3 & 100 & 100 & 5 & 6 & 83 & 89 & 46 \\
\hline Total & $0 \pm 12$ & $49 \pm 36$ & $81 \pm 22$ & $4 \pm 13$ & $-7 \pm 28$ & $44 \pm 27$ & $92 \pm 3$ & $37 \pm 8$ \\
\hline
\end{tabular}

* See Table I. Gran, granulocyte; mono, monocyte. $¥ \mathrm{PGE}_{1}\left(10^{-6} \mathrm{M}\right)$ inhibition at day 7, expressed as percentage reduction of control colony and cluster number. (Negative sign indicates enhanced growth with PGE . $_{1}$ ) $§ \mathrm{NE}$, not evaluable (exp. 3 had no monocyte colonies or clusters in the low HLA-DR density group [Table I]).

CML blood were found to stain adequately for ANAE activity, excluding the possibility that this stain would not detect monocyte colonies in CML.

Effect of $P G E_{1}$ on myeloid progenitor cell subsets in NBM and $C M L$. The inhibitory effects of $10^{-6} \mathrm{MPGE}_{1}$ on granulocyte, mixed $\mathrm{G} / \mathrm{M}$, and monocyte colonies and clusters were evaluated at days 7 and 14 for both NBM and CML, with the cumulative results of 16 experiments shown in Table $V$ and Fig. 2. As expected, $10^{-6} \mathrm{M} \mathrm{PGE}_{1}$ markedly inhibited pure monocyte colony and cluster formation in NBM, but it also effectively inhibited pure monocyte colony-forming cells (CFU) in CML. For example, $\mathrm{PGE}_{1}$ inhibition of NBM monocyte colonies and clusters at day 7 was $95 \pm 10 \%(n=8)$, compared with $89 \pm 21 \%(n=8)$ for CML (Table V). The inhibition of mixed colony and cluster formation by $\mathrm{PGE}_{1}$ was substantial for both NBM and CML, though generally less than the inhibition observed for pure monocyte colonies. Granulocyte colonies and clusters were generally resistant to the inhibitory effects of $\mathrm{PGE}_{1}$ in both NBM and CML. Overall colony and cluster inhibition by $\mathrm{PGE}_{1}$, however, was less in CML compared with NBM on both days 7
(13 \pm 12 vs. $32 \pm 8 \%, P=0.01)$ and day $14(31 \pm 10$ vs. $43 \pm 13 \%$, $P=0.2$ ).

Although the degree of inhibition of CFU-GM subsets was similar for NBM and CML at $10^{-6} \mathrm{M} \mathrm{PGE}_{1}$, it was possible that differences in the pattern of colony inhibition may become apparent at lower $P G E_{1}$ concentrations. To evaluate this possibility, the inhibiting effects of $10^{-6}, 10^{-8}$, and $10^{-10} \mathrm{M} \mathrm{PGE}_{1}$ were tested, with the data from two representative experiments shown in Table VI. For NBM, the inhibition of ANAE+ colonies (mixed GM plus monocyte) by $10^{-6}, 10^{-8}$, and $10^{-10} \mathrm{M} \mathrm{PGE}_{1}$ was $82 \pm 4$, $63 \pm 6$, and $28 \pm 11 \%$, respectively $(n=2)$. Corresponding data for CML revealed inhibition of $96 \pm 6,81 \pm 17$, and $50 \pm 17 \%$, respectively $(n=3)$. However, the low number of monocyte colonies in these CML cases does not allow us to conclude with certainty that CML monocyte progenitor cells are as sensitive to PGE as are NBM progenitor cells. The inhibition of granulocyte colonies was negligible for both groups over this $\mathrm{PGE}_{1}$ dose range.

These data suggest that overall colony inhibition by PGE may be partly determined by the initial percentage of ANAE+

Table III. Dose Response of PGE Inhibition as a Function of HLA-DR Antigen Density

\begin{tabular}{|c|c|c|c|c|c|}
\hline \multirow{2}{*}{$\begin{array}{l}\text { HLA-DR antigen } \\
\text { density* }\end{array}$} & \multirow{2}{*}{$\begin{array}{l}\text { PGE }_{1} \\
\text { concentration }\end{array}$} & \multicolumn{4}{|c|}{ Colonies and clusters (day 7) per $10^{3}$ cells } \\
\hline & & Granulocyte & Mixed G/M & Monocyte & Total \\
\hline \multirow[t]{6}{*}{ Low } & Control & $420 \pm 17 \ddagger$ & $2 \pm 1$ & $6 \pm 1$ & $428 \pm 17$ \\
\hline & $10^{-6} \mathrm{M}$ & $406 \pm 25(3 \%) \S$ & $0 \pm 0(100)$ & $0 \pm 0(100)$ & $406 \pm 25(5)$ \\
\hline & $10^{-7}$ & $414 \pm 13(1)$ & $1 \pm 1(50)$ & $0 \pm 0(100)$ & $414 \pm 14(3)$ \\
\hline & $10^{-8}$ & $425 \pm 32(-1)$ & $1 \pm 1(50)$ & $2 \pm 1(67)$ & $427 \pm 32(0)$ \\
\hline & $10^{-9}$ & $422 \pm 13(-1)$ & $1 \pm 1(50)$ & $3 \pm 1(50)$ & $426 \pm 11(1)$ \\
\hline & $10^{-10}$ & $443 \pm 14(-5)$ & $2 \pm 1(0)$ & $4 \pm 1(33)$ & $449 \pm 14(-5)$ \\
\hline \multirow[t]{6}{*}{ High } & Control & $159 \pm 14$ & $29 \pm 5$ & $119 \pm 4$ & $307 \pm 23$ \\
\hline & $10^{-6} \mathrm{M}$ & $150 \pm 2$ & $5 \pm 1(83)$ & $13 \pm 6(89)$ & $167 \pm 7$ \\
\hline & $10^{-7}$ & $152 \pm 6$ & $6 \pm 2(79)$ & $15 \pm 2(87)$ & $174 \pm 8$ \\
\hline & $10^{-8}$ & $162 \pm 4(-2)$ & $13 \pm 1(55)$ & $34 \pm 3(71)$ & $209 \pm 3$ \\
\hline & $10^{-9}$ & $162 \pm 3(-2)$ & $21 \pm 2(28)$ & $64 \pm 6(46)$ & $247 \pm 7 \quad(20)$ \\
\hline & $10^{-10}$ & $164 \pm 8 \quad(-3)$ & $24 \pm 2(17)$ & $88 \pm 6(26)$ & $276 \pm 15(10)$ \\
\hline
\end{tabular}

\footnotetext{
* NBM progenitor cells were separated on the basis of HLA-DR antigen density and plated in varying concentrations of $P E_{1}\left(10^{-6} \mathrm{M}^{-10^{-10}} \mathrm{M}\right)$ as indicated. ‡ See Table $\mathrm{I}$. § Numbers in parentheses indicate percentage $\mathrm{PGE}_{1}$ colony and cluster inhibition (negative sign indicates enhanced growth with $\mathrm{PGE}_{1}$ ).
} 
Table IV. Colony and Cluster Composition of NBM and CML Peripheral Blood*

\begin{tabular}{|c|c|c|c|c|c|}
\hline \multirow[b]{2}{*}{ Day } & \multirow[b]{2}{*}{ CFU-GM source } & \multicolumn{4}{|c|}{ Colony and cluster composition (\%) $\ddagger$} \\
\hline & & Granulocyte & Mixed G/M & Monocyte & Total ANAE positive \\
\hline \multirow[t]{2}{*}{7} & $\operatorname{NBM}(n=9)$ & $73 \pm 7 \quad(61-82) \S$ & $13 \pm 14(4-22)$ & $14 \pm 6(3-30)$ & $28 \pm 7 \quad(18-39)$ \\
\hline & $\operatorname{CML}(n=9)$ & $92 \pm 6 \quad(79-97)$ & $5 \pm 7 \quad(1-20)$ & $3 \pm 3(1-9)$ & $9 \pm 6 \quad(3-21)$ \\
\hline \multirow[t]{2}{*}{14} & $\operatorname{NBM}(n=3)$ & $64 \pm 8 \quad(55-71)$ & $19 \pm 7 \quad(11-24)$ & $17 \pm 9(8-24)$ & $36 \pm 8 \quad(29-45)$ \\
\hline & $\operatorname{CML~}(n=3)$ & $84 \pm 12(71-94)$ & $14 \pm 11(5-26)$ & $2 \pm 1(1-3)$ & $16 \pm 12(6-29)$ \\
\hline
\end{tabular}

\footnotetext{
* Myeloid progenitor cells were partially purified from either NBM or CML peripheral blood and plated in agar culture containing $10^{-6} \mathrm{M}$ indomethacin and $10 \%$ GCT as a source of colony-stimulating activity. ¥ Colony and cluster morphology was identified by combined esterase staining as described in text. $\S$ Results are expressed as mean percentage $\pm \mathrm{SE}$ of duplicate cultures. Numbers in parentheses indicate range.
}

colonies in either NBM or CML. As shown in Fig. 2, a plot of these two variables (percentage PGE inhibition vs. percentage ANAE + colonies) suggests a positive correlation, although this is exaggerated by the fact that the percentage of ANAE+ colonies is generally higher for NBM than for CML (Table IV). To correct for this, a regression of PGE inhibition on percentage of ANAE+ colonies and an indicator variable for CML was fit (26). This analysis revealed that PGE inhibition is significantly associated with the initial percentage of ANAE+ colonies $(0.001<P$ $<0.005$ ), regardless of CFU-GM source (NBM or CML).

Differentiation of myeloid progenitor cells in suspension culture. In an attempt to further evaluate the production of monocytes by CML progenitor cells, as well as to determine correlation between Wright Giemsa and combined esterase-staining techniques, partially purified preparations of NBM and CML peripheral blood were grown in liquid suspension culture as described, with or without $10^{-6} \mathrm{M} \mathrm{PGE}_{1}$. Table VII shows the cell count, cell composition by Wright-Giemsa, and percentage of ANAE + cells on days 0,7 , and 14 of suspension culture. Although the day 0 population of progenitor cells for NBM and CML differ with respect to enrichment of blast cells (due to more contamination by promyelocytes in the NBM preparation), there were $<1 \%$ monocytes in either population by WrightGiemsa' staining or ANAE positivity. At day 7, immature monocytes were detected in both NBM and CML preparations ( $8 \pm 4$ vs. $12 \pm 3 \%$, respectively), although ANAE staining was often weak in these cells. By day 14, however, the majority of cells in the NBM suspension culture were monocytes or macrophages by Wright-Giemsa stain $(76 \pm 10 \%)$, as opposed to a significantly smaller percentage of these cells in the CML suspension culture $(19 \pm 6 \%) \quad(P<0.025)$. Correlation between Wright-Giemsa staining and ANAE positivity in the day 14 control populations was excellent for both NBM and CML (Table VII). As expected,
$\mathrm{PGE}_{1}$ resulted in a reduction in the percentage of macrophages for both NBM and CML suspension cultures at days 7 and 14 .

\section{Discussion}

The detection of HLA-DR surface molecules on hematopoietic progenitor cells has created considerable interest, particularly with the finding of an association between DR antigen expression by CFU-GM and the in vitro growth regulation of these cells by inhibitory factors such as acidic isoferritins or PGE $(11,12)$. Further, the insensitivity of CML CFU-GM to the inhibitory effects of $\mathrm{PGE}_{1}$ has been related to a lower amount of $\mathrm{DR}$ antigen as detected by complement lysis techniques $(12,13)$. By using more sensitive assay techniques, however, we $(15,17,23)$ and others (16) have found that virtually all CFU-GM from both NBM and CML peripheral blood express detectable levels of DR antigen, making it unlikely that DR antigen expression is the sole determinant of CFU-GM sensitivity to PGE.

In this report, we have investigated the possibility that high HLA-DR antigen density on myeloid progenitor cells, rather than the expression of HLA-DR per se, identifies a subset of CFU-GM that is sensitive to the inhibitory effects of $\mathrm{PGE}_{1}$. Partially purified myeloid progenitor cells from NBM were separated by cell sorting into two fractions on the basis of HLA-DR antigen density, and CFU-GM subsets were determined by ANAE and CAE staining of agar cultures. Partial purification of NBM progenitor cells provided an enriched population of $\mathrm{DR}+$ cells ( $\sim 30 \%$ HLA-DR + ), and thus facilitated sorting of CFU-GM on the basis of DR antigen density. Furthermore, partial purification of CFU-GM also minimized the possible effects of accessory cells (monocytes, $\mathrm{T}$ lymphocytes) in the inhibition of colony growth by $\mathrm{PGE}_{1}$.

Analysis of day 7 colonies and clusters revealed a significant

Table V. PGE $E_{1}$ Inhibition of CFU-GM Subsets from NBM and CML-Cumulative Results

\begin{tabular}{|c|c|c|c|c|c|}
\hline \multirow[b]{2}{*}{ Day } & \multirow[b]{2}{*}{ CFU-GM source } & \multicolumn{4}{|c|}{ Percent inhibition of CFU-GM by $10^{-6} \mathrm{M} \mathrm{PGE}_{1}$} \\
\hline & & Granulocyte & Mixed G/M & Monocyte & Total \\
\hline \multirow[t]{2}{*}{7} & $\operatorname{NBM}(n=8)$ & $16 \pm 10(3-27)^{*}$ & $62 \pm 18(40-88)$ & $95 \pm 10(95-100)$ & $32 \pm 8 \quad(23-45)$ \\
\hline & $\operatorname{CML}(n=8)$ & $12 \pm 15(0-35)$ & $54 \pm 24(25-89)$ & $89 \pm 21(54-100)$ & $13 \pm 12(2-37)$ \\
\hline \multirow[t]{2}{*}{14} & $\operatorname{NBM}(n=3)$ & $24 \pm 16(9-40)$ & $59 \pm 51(0-96)$ & $88 \pm 17(69-100)$ & $43 \pm 13(31-56)$ \\
\hline & $\operatorname{CML}(n=3)$ & $19 \pm 9 \quad(12-29)$ & $74 \pm 22(50-93)$ & $100 \pm 0 \quad(-)$ & $31 \pm 10(19-37)$ \\
\hline
\end{tabular}

\footnotetext{
* See Table IV. Results expressed as mean percent inhibition \pm SE. Numbers in parentheses indicate range.
} 


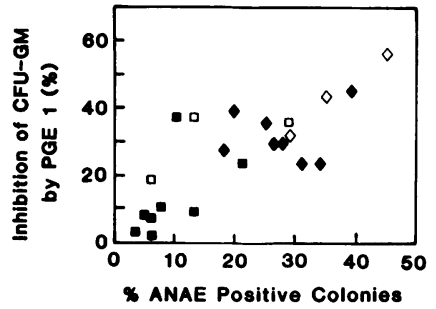

Figure 2. PGE $_{1}$-mediated inhibition of CFU-GM as a function of initial percentage of mixed and monocyte colonies as defined by ANAE staining. Closed diamonds: NBM, day 7; open diamonds: NBM, day 14; closed squares: CML, day 7; open squares: CML, day 14.

enrichment of pure monocyte progenitor cells in the high density DR + fraction, and an enrichment of granulocyte progenitor cells in the low density DR+ fraction. Inhibition of colony growth by PGE tended to be greater in the high DR+ fraction of CFU$\mathrm{GM}$, and this correlated with the higher percentage of monocyte colonies observed in this progenitor cell population. When each CFU-GM subset was examined individually for $\mathrm{PGE}_{1}$ sensitivity, inhibition was found to be largely restricted to the monocyte progenitor cells, and this appeared to be true whether these cells were in the high DR+ or low DR+ fractions. These findings suggest that the association between HLA-DR antigen expression by normal CFU-GMs and inhibition by PGE is related to the fact that high levels of HLA-DR select for progenitor cells that are committed to monocyte differentiation. Although inhibition of monocyte progenitor cells by PGE has been observed by previous investigators (27-29), an association between high HLADR density and commitment to monocyte differentiation has not been previously described.

It should be noted that these data do not exclude the possibility that HLA-DR antigen density may be functionally important in the mediation of prostaglandin colony inhibition, independent of monocyte progenitor cell enrichment. However, the fact that no major difference was demonstrated in the PGEmediated inhibition of different CFU-GM subsets in either the high or low HLA-DR groups suggests that DR antigen density may not independently define a progenitor cell's sensitivity to inhibition by PGE. Nevertheless, in view of the difficulty in accurately quantitating the degree of PGE inhibition of monocyte colonies in the low DR density fraction (due to low numbers of monocyte progenitor cells in control cultures), we cannot conclude with certainty that there is equal sensitivity to PGE of monocyte progenitor cells in the low and high $\mathrm{DR}+$ fractions.
The relationship between HLA-DR antigen expression, commitment to monocyte differentiation, and colony inhibition by PGE was evaluated further by studying CFU-GM in CML, a stem cell disorder in which there is relative resistance to the inhibitory effects of PGE (30-33) despite the presence of HLADR on virtually all CFU-GM (15). In view of the selectivity of PGE for monocyte precursor cells, we considered the possibility that the lack of PGE inhibition in CML may be related to a relative decrease of monocyte colony-forming units in this disease. Previous investigators using other techniques to identify colony morphology including Luxol Fast Blue staining (32) and Giemsa staining $(30,31)$ have reported that the ratio of monocyte to granulocyte colonies in CML and NBM is similar. Morphological analysis of colony or cluster subtype, however, may be difficult without the use of lineage-specific stains. Early granulocyte colonies may contain large numbers of myelocytes, metamyelocytes, and band forms that may appear monocytoid. In view of these considerations, we reevaluated prostaglandin-mediated inhibition of CFU-GM in both NBM and CML peripheral blood using combined esterase staining of entire agar overlayers. This technique has the potential advantage of more accurate identification of colony and cluster lineage and avoids the problem of sampling error that may be associated with micropipette manipulation of individual colonies.

The results of 18 experiments demonstrate a statistically significant decrease in the proportion of mixed $\mathrm{G} / \mathrm{M}$ and monocyte colony-forming cells in CML when compared with NBM. This finding was not related to an inability of CML-derived monocytes to stain for ANAE, since excellent correlation was observed between Wright-Giemsa and ANAE staining of monocytes freshly isolated from CML peripheral blood. Further, cultures of partially purified progenitor cells in suspension culture also revealed a relative decrease of mature monocytes compared with NBM in CML, again with good correlation between Wright-Giemsa morphology and ANAE staining in both CML and NBM cultures.

Despite differences in the composition of CFU-GM subsets in NBM and CML, CFU-GM subsets from either source appeared to be inhibited by PGE to a similar degree, with granulocyte progenitor cells being least sensitive, and monocyte progenitor cells most sensitive, to PGE inhibition. In CML, however, the infrequency of monocyte progenitor cells makes it difficult

Table VI. Dose Response of PGE, Inhibition in CFU-GM Subsets of NBM and CML*

\begin{tabular}{|c|c|c|c|c|c|}
\hline \multirow[b]{2}{*}{ CFU-GM sourceł } & \multirow{2}{*}{$\begin{array}{l}\text { PGE } \\
\text { concentration }\end{array}$} & \multicolumn{4}{|c|}{ Colonies and clusters (day 7) $\$$} \\
\hline & & Granulocyte & Mixed G/M & Monocyte & Total \\
\hline \multirow[t]{4}{*}{ NBM } & Control & $66 \pm 4$ & $4 \pm 2$ & $30 \pm 2$ & $100 \pm 6$ \\
\hline & $10^{-6} \mathrm{M}$ & $72 \pm 2 \quad(-9)^{\prime \prime}$ & $2 \pm 1(50)$ & $5 \pm 1(83)$ & $77 \pm 3$ \\
\hline & $10^{-8}$ & $71 \pm 2 \quad(-8)$ & $3 \pm 1(25)$ & $11 \pm 2(63)$ & $84 \pm 2 \quad(16)$ \\
\hline & $10^{-10}$ & $71 \pm 2 \quad(-8)$ & $4 \pm 2(0)$ & $17 \pm 3(43)$ & $92 \pm 1 \quad(8)$ \\
\hline \multirow[t]{4}{*}{ CML } & Control & $193 \pm 10$ & $2 \pm 1$ & $7 \pm 1$ & $201 \pm 10$ \\
\hline & $10^{-6}$ & $183 \pm 8$ & $0 \pm 0(100)$ & $1 \pm 1(86)$ & $184 \pm 7 \quad(8)$ \\
\hline & $10^{-8}$ & $188 \pm 10(3)$ & $1 \pm 1(50)$ & $2 \pm 1(71)$ & $185 \pm 10(8)$ \\
\hline & $10^{-10}$ & $186 \pm 7$ & $2 \pm 1(0)$ & $4 \pm 1(43)$ & $195 \pm 8$ \\
\hline
\end{tabular}

* Two representative experiments of five. ¥ See Table IV. After partial purification of CFU-GM, cells were plated in varying concentrations of $\mathrm{PGE}_{1}$ in the presence of $10^{-6} \mathrm{M}$ indomethacin and $10 \% \mathrm{GCT}$ as a source of colony-stimulating activity. $\S$ Results are expressed as mean number $\pm \mathrm{SE}$ of triplicate cultures per $10^{3}$ cells as determined on day 7 by combined esterase staining. "Numbers in parentheses indicate percent PGE colony plus cluster inhibition. 
Table VII. Differentiation of Partially Purified Myeloid Progenitor Cells in Suspension Culture*

\begin{tabular}{|c|c|c|c|c|c|c|c|c|}
\hline Cell source & $\begin{array}{l}\text { Incubation } \\
\text { time }\end{array}$ & $\mathrm{PGE}_{1}\left(10^{-6} \mathrm{M}\right)$ & Cell no. $\left(\times 10^{6}\right)$ & Blasts & Promyelocytes & $\begin{array}{l}\text { Myelocytes- } \\
\text { granulocytes" }\end{array}$ & $\begin{array}{l}\text { Monocytic } \\
\text { cells }\end{array}$ & $\begin{array}{l}\text { ANAE positive } \\
\text { cellst }\end{array}$ \\
\hline \multirow[t]{5}{*}{ NBM } & Day 0 & & $1.0 \ddagger$ & $31 \pm 8 \S$ & $50 \pm 4$ & $19 \pm 6$ & $0 \pm 0$ & $1 \pm 0$ \\
\hline & Day 7 & - & 10.4 & $1 \pm 1$ & $44 \pm 9$ & $47 \pm 8$ & $8 \pm 4$ & $1 \pm 0$ \\
\hline & & + & 7.7 & $2 \pm 1$ & $26 \pm 6$ & $69 \pm 9$ & $3 \pm 2$ & $1 \pm 0$ \\
\hline & Day 14 & - & 4.4 & $1 \pm 1$ & $6 \pm 3$ & $17 \pm 2$ & $76 \pm 10$ & $75 \pm 12$ \\
\hline & & + & 4.2 & $3 \pm 1$ & $34 \pm 8$ & $27 \pm 4$ & $36 \pm 6$ & $18 \pm 13$ \\
\hline \multirow[t]{5}{*}{$\mathrm{CML}$} & Day 0 & & 1.0 & $98 \pm 3$ & $2 \pm 1$ & $0 \pm 0$ & $0 \pm 0$ & $1 \pm 0$ \\
\hline & Day 7 & - & 15.5 & $12 \pm 5$ & $62 \pm 7$ & $14 \pm 4$ & $12 \pm 3$ & $2 \pm 1$ \\
\hline & & + & 11.8 & $15 \pm 3$ & $64 \pm 4$ & $20 \pm 4$ & $1 \pm 1$ & $1 \pm 0$ \\
\hline & Day 14 & - & 16.4 & $0 \pm 0$ & $15 \pm 3$ & $66 \pm 7$ & $19 \pm 6$ & $18 \pm 4$ \\
\hline & & + & 18.4 & $5 \pm 3$ & $28 \pm 5$ & $66 \pm 9$ & $1 \pm 3$ & $2 \pm 1$ \\
\hline
\end{tabular}

* Cells for suspension culture were obtained by partial purification of either NBM or CML as previously described. ‡ For each treatment group, $1 \times 10^{6}$ partially purified progenitor cells were suspended in $5 \mathrm{ml}$ of $20 \%$ FCS IMDMEM medium containing $10^{-6} \mathrm{M}$ indomethacin and plated in a $60 \times 15-\mathrm{mm}$ petri dish on day 0 . § Differential count expressed as mean percent \pm SE as determined by Wright-Giemsa staining (300 cells counted). "Myelocyte, metamyelocyte, band, and polymorphonuclear leukocyte. I Mean percent \pm SE of monocytic cells as determined by ANAE staining ( 300 cells counted).

to compare their sensitivity to PGE with that of normal monocyte progenitor cells. Nevertheless, these results suggest that the overall resistance to PGE inhibition in CML may be partly explained on the basis of a decreased percentage of monocyte precursors. A significant correlation was demonstrated between the initial percentage of mixed and monocyte colonies and the final degree of prostaglandin inhibition obtained, regardless of the source of progenitor cells (NBM or CML), further supporting this concept (Fig. 2). This correlation is not exact because inhibition of mixed colonies and clusters was rarely complete, and because there was often a small degree of granulocyte inhibition by $\mathrm{PGE}_{1}$ in both NBM and CML samples. The direct relationship observed between the percentage of monocyte precursor cells and the degree of $\mathrm{PGE}_{1}$ inhibition of colony and cluster growth suggests that the blunted response to prostaglandin in CML is at least partly due to a decreased proportion of sensitive target cells in this disease, as opposed to deficient progenitor cell HLADR antigen expression.

\section{Acknowledgments}

The authors would like to thank Dr. George P. Canellos for his advice and assistance during this study.

This work was supported in part by U. S. Public Health Service grants CA36167, CA19389 project 3, and 5T32CA09172-09. Dr. Cannistra is a Fellow of the Johanna C. Wood Foundation, and Dr. Griffin is a Scholar of the Leukemia Society of America.

\section{References}

1. Fitchen, J. H., C. LeFevre, S. Ferrone, and M. J. Cline. 1982. Expression of Ia-like and HLA-A, B antigens on human multipotential hematopoietic progenitor cells. Blood. 59:188-190.

2. Schlossman, S. F., L. Chess, R. E. Humphreys, and J. L. Strominger. 1976. Distribution of Ia-like molecules on the surface of normal and leukemic human cells. Proc. Natl. Acad. Sci. USA. 73:1288-1292.

3. Winchester, R. J., G. D. Ross, C. I. Jarowski, C. Y. Wang, J. Halper, and H. E. Broxmeyer. 1977. Expression of Ia-like antigen molecules on human granulocytes during early phases of differentiation. Proc. Natl. Acad. Sci. USA. 74:4012-4016.
4. Winchester, R. J., P. A. Meyers, H. E. Broxmeyer, C. Y. Wang, D. Moore, and H. G. Kunkel. 1978. Inhibition of human erythropoietic colony formation in culture by treatment with Ia antisera. J. Exp. Med. 148:613-618.

5. Janossy, G., G. F. Francis, D. Capellaro, A. H. Goldstone, and M. F. Greaves. 1978. Cell sorter analysis of leukemia-associated antigens on human myeloid precursors. Nature (Lond.). 276:176-178.

6. Robinson, J., C. Sieff, D. Delia, P. A. W. Edwards, and M. Greaves. 1981. Expression of cell surface HLA-DR, HLA-A, B, C, and glycophorin during erythroid differentiation. Nature (Lond.). 289:68-71.

7. Bach, F. H., and J. J. van Rood. 1976. The major histocompatibility complex-genetics and biology. N. Engl. J. Med. 295:806-813.

8. Benacerraf, B. 1981. Role of MHC gene produces in immune regulation. Science (Wash. DC). 212:1229-1238.

9. Greigheny, C., and P. Stastny. 1979. HLA-D region-associated determinants serve as targets for human cell-mediated lysis. J. Exp. Med. 149:485-494.

10. Breard, J., A. Fuks, S. M. Friedman, S. F. Schlossman, and L. Chess. 1979. The role of p23,30-bearing human macrophages in antigeninduced T lymphocyte responses. Cell Immunol. 45:108-119.

11. Broxmeyer, H. E. 1982. Relationship of cell cycle expression of Ia-like antigenic determinants on normal and leukemia human granulocyte-macrophage progenitor cells to regulation in vitro by acidic isoferritins. J. Clin. Invest. 69:631-642.

12. Pelus, L. M., S. Saletan, R. Silver, and M. A. Moore. 1982. Expression of Ia antigens on normal and chronic myeloid leukemic human granulocyte-macrophage colony forming cells is associated with the regulation of cell proliferation by prostaglandin E. Blood. 59:284-292.

13. Pelus, L. M., E. Gold, S. Saletan, and M. Coleman. 1983. Restoration of responsiveness of chronic myeloid leukemia granulocytemacrophage colony forming cells to growth regulation in vitro following preincubation with prostaglandin E. Blood. 62:158-165.

14. Schwamborn, J. S., S. Ferrone, and J. H. Fitchen. 1984. Prostaglandin E (PGE)-mediated inhibition of granulocyte-macrophage progenitors (CFU-GM) from patients with chronic granulocytic leukemia (CGL). Blood. 64:198a. (Abstr. 702)

15. Cannistra, S. A., J. F. Daley, P. Larcom, and J. D. Griffin. 1985. Expression of Ia antigens on myeloid progenitor cells in chronic myeloid leukemia: direct analysis using partially purified colony forming cells. Blood. 65:414-422.

16. Fitchen, J. H., and D. R. Burger. 1983. Heterogeneity of Ia antigen 
density on human granulocyte-macrophage progenitor cells. Blood. 62 : 134a. (Abstr. 440)

17. Griffin, J. D., J. Ritz, L. M. Nadler, and S. F. Schlossman. 1981. Expression of myeloid differentiation antigens on normal and malignant cells. J. Clin. Invest. 68:932-941.

18. Todd, R. F., L. M. Nadler, and S. F. Schlossman. 1981. Antigens on human monocytes identified by monoclonal antibodies. J. Immunol. 126:1435-1442.

19. Stashenko, P., L. M. Nadler, R. Hardy, and S. F. Schlossman. 1980. Characterization of a human B lymphocyte specific antigen. $J$. Immunol. 125:1678-1685.

20. Reinherz, E. L., S. Meuer, K. A. Fitzgerald, R. E. Hussey, H. Levine, and S. F. Schlossman. 1982. Antigen recognition by human $T$ lymphocytes is linked to surface expression of the T3 molecular complex. Cell. 30:735-743.

21. Meuer, S. C., R. E. Hussey, M. Fabbi, D. Fox, O. Acuto, K. Fitzgerald, J. Hodgdon, J. Protentis, S. F. Schlossman, and E. L. Reinherz. 1984. An alternate pathway of $T$ cell activation: a functional role for the 50kD T11 sheep erythrocyte receptor protein. Cell. 36:897-906.

22. Griffin, J. D., T. Hercend, R. P. Beveridge, and S. F. Schlossman. 1983. Characterization of an antigen expressed by human natural killer cells. J. Immunol. 130:2947-2951.

23. Griffin, J. D., R. P. Beveridge, and S. F. Schlossman. 1982. Isolation of myeloid progenitor cells from peripheral blood of chronic myelogeneous leukemia patients. Blood. 60:30-37.

24. Todd, R. F., S. C. Meuer, P. L. Romain, and S. F. Schlossman. 1984. A monoclonal antibody that blocks class II histocompatibilityrelated immune interactions. Human Immunol. 10:23-40.
25. Kubota, K., H. Mizoguchi, Y. Miura, T. Suda, and F. Takaku. 1980. A new technique for the cytochemical examination of human hematopoietic cells grown in agar gel. Exp. Hematol. 8:339-344.

26. Snedecor, G. W., and W. G. Cochran. 1967. Statistical Methods. Iowa State University Press, Iowa. 91-92, 114-116, 180-181.

27. Williams, N. 1979. Preferential inhibition of murine macrophage colony formation by prostaglandin E. Blood. 53:1089-1094.

28. Pelus, L. M., H. E. Broxmeyer, J. I. Kurland, and M. A. S. Moore. 1979. Regulation of macrophage and granulocyte proliferation: specificities of prostaglandin E and lactoferrin. J. Exp. Med. 150:277-292.

29. Gentile, P., D. Byer, and L. M. Pelus. 1983. In vitro modulation of murine myelopoiesis following intravenous administration of prostaglandin E2. Blood. 62:1100-1107.

30. Aglietta, M., W. Piacibello, and F. Gavosto. 1980. Insensitivity of chronic myeloid leukemia cells to inhibition of growth by prostaglandin E. Cancer Res. 40:2507-2511.

31. Aglietta, M., W. Piacibello, and F. Gavosto. 1981. Prostaglandins and myelopoiesis: effect of prostaglandin E1 on normal and chronic myeloid leukemia colony forming cells (CFU-GM) subpopulations. Cell Biology International Reports. 5:836.

32. Pelus, L. M., H. E. Broxmeyer, B. D. Clarkson, and M. A. S. Moore. 1980. Abnormal responsiveness of granulocyte-macrophage committed colony forming cells from patients with chronic myeloid leukemia to inhibition by prostaglandin E. Cancer Res. 40:2512-2515.

33. Taetle, R., and S. Li-en. 1984. Further studies on mechanisms of abnormal prostaglandin response by chronic myelogeneous leukemia granulocyte/macrophage progenitors. Leukemia Res. 8:833-842. 